\title{
Analysis and Comparison Based on Component Stress Factor of Dual Active Bridge and Isolated Full Bridge Boost Converters for Bidirectional Fuel Cells Systems
}

Pittini, Riccardo; Mira Albert, Maria del Carmen; Zhang, Zhe; Knott, Arnold; Andersen, Michael A. E.

Published in:

Proceedings of IEEE International Power Electronics and Application Conference and Exposition

Publication date:

2014

Link back to DTU Orbit

Citation (APA):

Pittini, R., Mira Albert, M. D. C., Zhang, Z., Knott, A., \& Andersen, M. A. E. (2014). Analysis and Comparison Based on Component Stress Factor of Dual Active Bridge and Isolated Full Bridge Boost Converters for Bidirectional Fuel Cells Systems. In Proceedings of IEEE International Power Electronics and Application Conference and Exposition (pp. 1026-1031). IEEE.

- You may freely distribute the URL identifying the publication in the public portal 


\title{
Analysis and Comparison Based on Component Stress Factor of Dual Active Bridge and Isolated Full Bridge Boost Converters for Bidirectional Fuel Cells Systems
}

\author{
Riccardo Pittini, Maria C. Mira, Zhe Zhang, Arnold Knott, Michael A.E. Andersen \\ Technical University of Denmark, Dept. of Electrical Engineering \\ Oersteds Plads 349, 2800 Kgs. Lygnby, Denmark \\ ripit@elektro.dtu.dk
}

\begin{abstract}
This paper presents an analysis and comparison of isolated topologies for bidirectional fuel cell systems. The analyzed topologies are the dual active bridge (DAB) and the isolated full bridge boost converter (IFBBC). The analysis is performed based on the component stress factor (CSF). Results highlight that the DAB has lower CSF than the IFBBC for narrow converter operating points. On the other hand the IFBBC presents a more homogeneous CSF over the entire converter operating range. Finally, experimental results obtained from a $30-80 \mathrm{~V} 80 \mathrm{~A} 6 \mathrm{~kW} 40 \mathrm{kHz}$ IFBBC are presented. The converter achieves efficiencies up to $98.2 \%$ and $97.45 \%$ depending on the converter power flow.
\end{abstract}

Keywords-Dual Active Bridge (DAB), Isolated full Bridge Boost Converter (IFBBC), Component Stress Factor (CSF), High Efficiency, Bidirectional Fuel Cells.

\section{INTRODUCTION}

Power converter's efficiency has been one of the major driving forces in power electronics especially over the last two decades. The latest developments in the power semiconductor technologies allowed developing converters with efficiency above 98\% even with isolated topologies [1],[2]. However, selecting the latest silicon carbide ( $\mathrm{SiC}$ ) power semiconductors [3] it is not sufficient to achieve high efficiency. It is necessary to perform an analysis and optimization of different solutions in terms of converter topology, power semiconductors, magnetic component design as well as converter optimization.

Large scale integration of renewable energies requires grid tie energy storage to balance the energy production and consumption [4]. For these applications bidirectional fuel cells represent an attractive technology [5]. However, bidirectional fuel cells, also called regenerative or reversible fuel cells (RFCs), have wider operating conditions than conventional unidirectional fuel cells. Choosing the most suitable topology that can guarantee good performance over the entire system operating range is always troublesome and challenging. This is especially true for fuel cells applications where power converters are expected to operate at low-voltage and highcurrent levels.
This paper presents an analysis of two isolated dc-dc converter topologies: the isolated full bridge boost converter (IFBBC) [2] and the dual active bridge (DAB) [6]. The two topologies are analyzed in terms of component stress factor [7],[8] and compared based on the converter specifications for bidirectional fuel cell applications. Based on the analysis, a $6 \mathrm{~kW}$ bidirectional dc-dc IFBBC has been developed. The converter prototype achieves peak efficiencies of $98.2 \%$ and $97.45 \%$ depending on the converter power flow.

\section{System ANALYSIS AND SPECIFICATIONS}

An energy storage bidirectional system based on regenerative fuel cells requires high efficiency dc-dc and dc-ac converters to effectively operate the system at its maximum performance. The cell technology strongly affects the system topology in fact, the voltage of a single cell is too low to realized multi-kW energy storage systems. It is necessary to stack several cells to achieve voltage levels that can better be processed by multi-kW power converters. Stacking a large number of cell increases the manufacturing challenges, such as homogeneous operating conditions of the cells stack and fuel pressure equalization. Moreover, not all fuel cells are suitable for bidirectional operation since operating in the two modes could significantly change the stress conditions of the cells and affect their reliability.

Based on a close cooperation with a large fuel cells manufacturer, it was determined that new solid oxide cell technology can be operated in both fuel cell mode (SOFC) and electrolyzer cell mode (SOEC). Table I shows the dc-dc converter specifications, which are defined based on a laboratory prototype of SOFC/SOEC cells stack. A $50 \mathrm{~kW}$

TABLE I

SOFC AND SOEC DC-DC CONVERTER SPECIFICATIONS

\begin{tabular}{lcc}
\hline & SOFC & SOEC \\
Low Voltage (LV) side & $30-50 \mathrm{~V}$ & $50-80 \mathrm{~V}$ \\
Current (LV) side & $40-0 \mathrm{~A}$ & $0-80 \mathrm{~A}$ \\
High Voltage (HV) side & $700-800 \mathrm{~V}$ & $700-800 \mathrm{~V}$ \\
Power Rating & $\sim 1500 \mathrm{~W}$ & $\sim 6000 \mathrm{~W}$ \\
\hline \hline
\end{tabular}




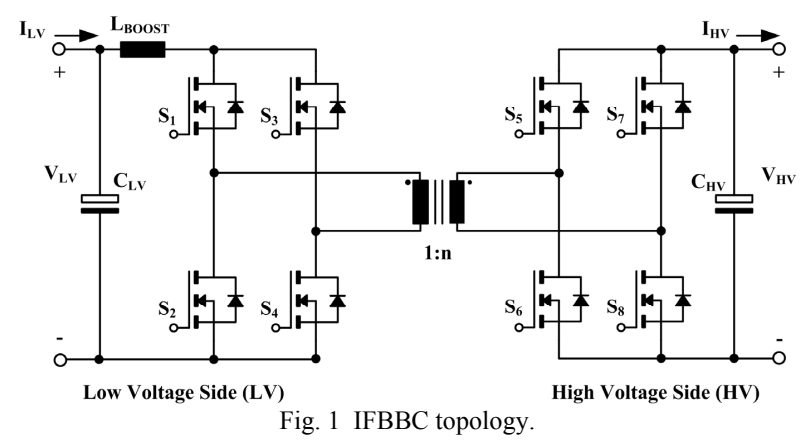

system for grid connected energy storage applications is presented in [9]. The system is composed by 10 cells stacks and each stack has a dc-dc converter. The operating mode of the system (SOFC or SOEC) determines the operating conditions of the dc-dc converter (I-V curve, [9]) and therefore, the system efficiency for the different operating points.

\section{ISOLATED TOPOLOGIES FOR BIDIRECTIONAL FUEL CELLS SysteMS: SELECTION AND ANALYSIS}

Different isolated topologies can be candidate for energy storage systems based on bidirectional fuel cells. However, resonant topologies have difficulties to achieve suitable high efficiency when the converter ports voltage varies significantly (e.g. in this application by a factor 2.6). Another factor that influences the selection of the topology is its complexity in terms of number of power semiconductors, passive components and control. All these parameters will significantly affect also the cost of the converter and the economical sustainability of the system.

The results from the analysis of different isolated dc-dc converter topologies highlighted two candidate topologies suitable for the system: the isolated full bridge boost converter (IFBBC) and the dual active bridge (DAB).

\section{A. Isolated Full Bridge Boost Converter (IFBBC)}

The IFBBC topology shown on Fig. 1, has proved to achieve efficiency up to $98 \%$ [2] in fuel cell applications. The main CCM operating waveforms are presented in Fig. 2. The boost inductor $L_{B O O S T}$ is the component that controls the energy transfer from the converter low voltage side to the high voltage side and it has to handle the high current level $I_{L V}$ on the converter low voltage side. Given an operating point, the duty cycle $(0.5<\mathrm{D}<1)$ is calculated according to (1).

$$
D=1-\frac{n V_{L V}}{2 V_{H V}}
$$

For a given converter switching frequency $\mathrm{f}_{\mathrm{SW}}=1 / \mathrm{T}_{\mathrm{SW}}$, the maximum and minimum boost inductor currents are expressed by (2) and (3) respectively. The transformer rms current of the low voltage side (4) can be calculated using (2) and (3).

$$
\begin{aligned}
& i_{0}=I_{L V}-\frac{V_{L V} T_{S W}(2 D-1)}{4 L} \\
& i_{1}=I_{L V}+\frac{V_{L V} T_{s w}(2 D-1)}{4 L}
\end{aligned}
$$

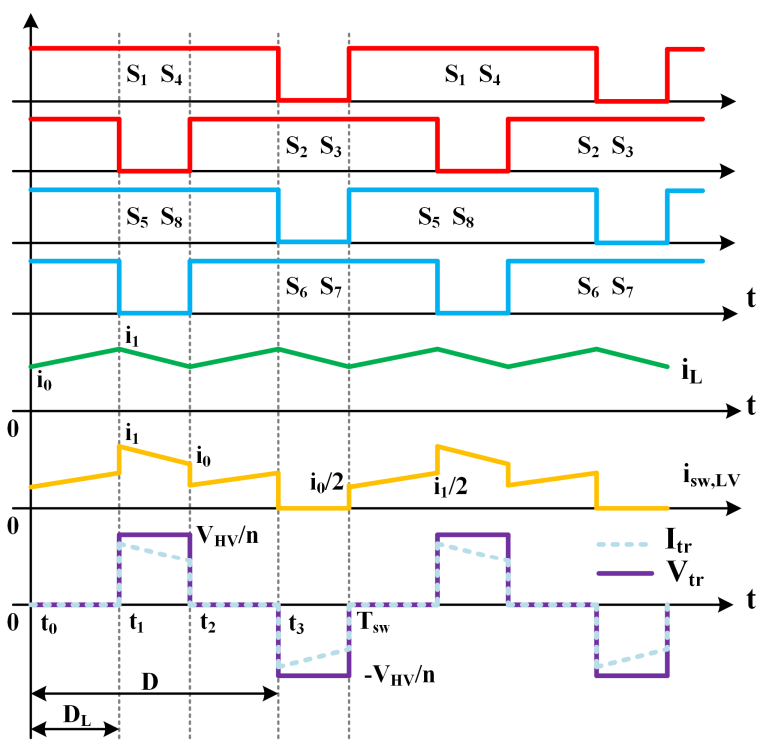

Fig. 2 IFBBC CCM main operating waveforms.

$$
I_{t r . L V, r m s}=\frac{\sqrt{2}}{\sqrt{3}} \sqrt{(1-D)\left(i_{0}^{2}+i_{1}^{2}+i_{0} i_{1}\right)}
$$

By neglecting the ripple in the boost inductor, it is possible to simplify (4) obtaining the transformer current in the low voltage winding as shown in (5).

$$
I_{t r . L V, r m s}=I_{L V} \sqrt{2(1-D)}
$$

Assuming ideal current distribution in the converter switches, during the intervals $\mathrm{t} 0$ - $\mathrm{t} 1$ and $\mathrm{t} 2 \mathrm{-t} 3$ each switch on the converter low voltage side carries $\mathrm{I}_{\mathrm{LV}} / 2$. During the intervals $\mathrm{t} 1-\mathrm{t} 2$ and $\mathrm{t} 3-\mathrm{Tsw}$ the full $\mathrm{I}_{\mathrm{LV}}$ current flows through the switch. This results that the rms current of the low voltage side switches can be calculated as in (6).

$$
I_{s w . L V, r m s}=I_{L V} \sqrt{\frac{3}{4}-\frac{D}{2}}
$$

The rms current of the high voltage side transformer winding and of the high voltage switches is expressed as a function of the current in the low voltage winding as in (7).

$$
I_{t r . H V, r m s}=\frac{I_{t r . L V, r m s}}{n} ; \quad I_{s w . H V, r m s}=\frac{I_{t r . L V, r m s}}{n \sqrt{2}} ;
$$

\section{B. Dual Active Bridge (DAB)}

In the DAB topology, shown in Fig. 3, the power flow is controlled through the ac-inductance in series with the transformer. Phase-shift modulation allows controlling the power flow in the converter with the phase-shift angle. By defining $\varphi$ the phase-shift angle between the primary full bridge and the secondary full bridge, the power transfer between the low-voltage and the high voltage sides of the converter can be expressed as in (8). The maximum power transfer is achieved for $\varphi=\pi / 2$; it can be observed that large 


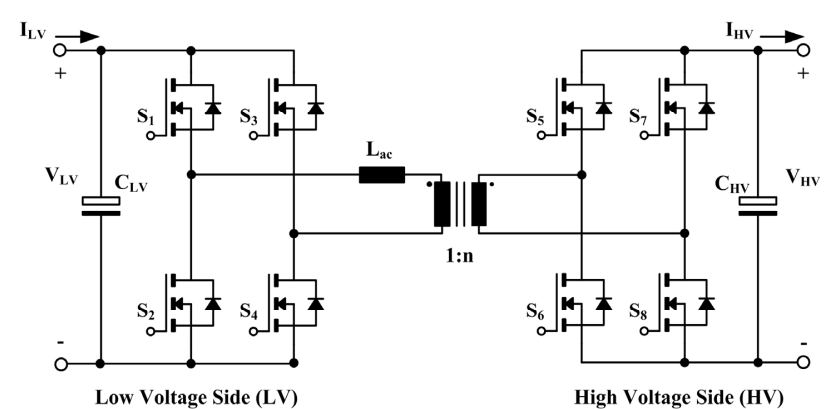

Fig. 3 DAB topology.

values of the $\mathrm{L}_{\mathrm{ac}}$ would limit the maximum power flow in the converter.

$$
P=\frac{V_{L V} V_{H V}}{n \omega L_{a c}} \varphi\left(1-\frac{\varphi}{\pi}\right)
$$

Defining the voltage transfer ratio as in (9) allows expressing the transformer current at time intervals t0 and $t 1$ as in (10) and in (11) respectively.

$$
\begin{gathered}
M=\frac{V_{H V}}{n V_{L V}} \\
i_{0}=\frac{-V_{L V}}{2 \omega L_{a c}}[(1-M)(\pi-\varphi)+(1+M) \varphi] \\
i_{1}=\frac{V_{L V}}{2 \omega L_{a c}}[(1+M) \varphi+(1-M)(\pi-\varphi)]
\end{gathered}
$$

The symmetry of the transformer current (12) allows expressing the rms transformer low voltage side current as in (13). The transformer current on the high voltage winding is related to the rms current on the transformer low voltage side by the turns ratio $n$. The ac-inductor current rms current is the same as the rms current of the transformer low voltage side winding. It is a common design procedure to integrate the acinductor in the transformer by tuning the transformer leakage inductance.

$$
\begin{array}{r}
i_{2}=-i_{0} ; \quad i_{3}=-i_{1} ; \\
I_{t r . L V, r m s}=\frac{1}{\sqrt{3}} \sqrt{i_{0}^{2}+i_{1}^{2}-i_{0} i_{1}+2 \frac{\varphi}{\pi} i_{0} i_{1}}
\end{array}
$$

The rms current of both low voltage and high voltage switches is defined as a function of the transformer low voltage windings rms current as in (14).

$$
I_{s w . L V, r m s}=\frac{I_{t r . L V, r m s}}{\sqrt{2}} ; \quad I_{s w . H V, r m s}=\frac{I_{t r . L V, r m s}}{n \sqrt{2}} ;
$$

\section{COMPONENT STRESS FACTOR ANALYSIS}

Component stress factor (CSF) is an analytical method used to evaluate and compare different converter topologies for a specific application. The method provides an estimation of the converter stresses and gives a quantitative measure of converter performance. The CSF method is similar to the component load factor (CLF) [4],[5], the difference in the two methods lies in how the individual and total components are calculated. In order to perform a fair comparison of the topologies, CSF assumes that the same amount silicon, magnetic material and capacitor volume are used on the analyzed topologies. This is

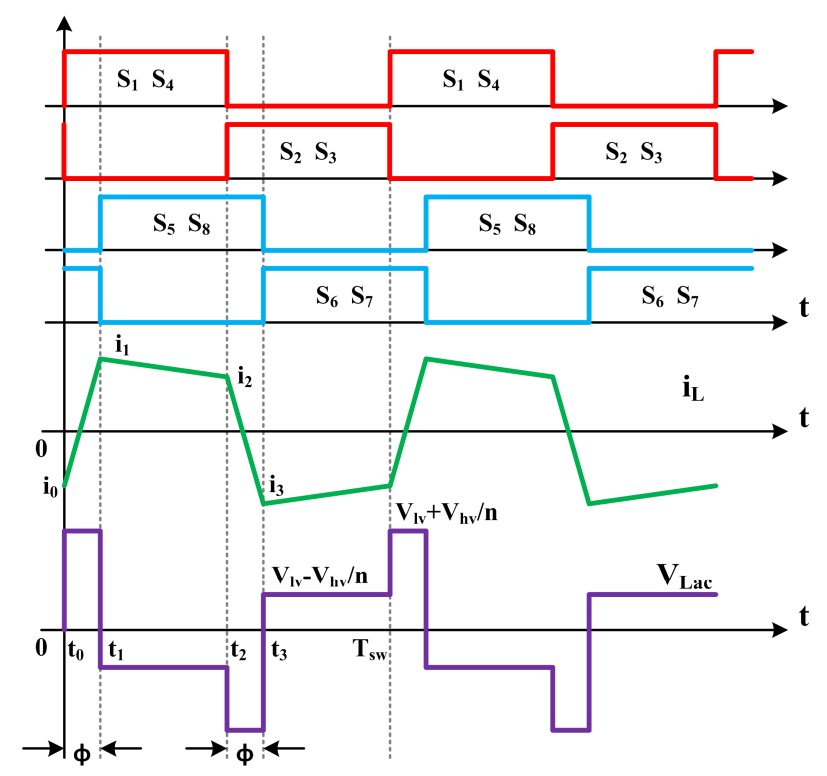

Fig. 4 DAB main operating waveforms with phase-shift modulation.

ensured by applying weighting factors to each component. The $\mathrm{CSF}$ analysis is performed based on three separate components: the semiconductor component stress factor (SCSF) (15), the winding component stress factor (WCSF) (16) and the capacitor component stress factor (CCSF) (17). The total stress over the different components is computed separately by adding together the relative components of the semiconductors (18), windings (19) and capacitors (20).

The different CSF values are calculated based on the devices voltages and rms currents. For power semiconductors the maximum voltage that the devices have to withstand over the entire converter operating range is considered. For wounded components, such as inductors and transformers, $V_{\max }$ represents the maximum averaged value (based on duty cycle). For capacitive components $V_{p k}$ is the maximum peak value. All the CSF values are scaled with the processed power, making the CSF a dimensionless quantity.

$$
\begin{aligned}
\operatorname{SCSF}_{i} & =\frac{\sum_{j} W_{j}}{W_{i}} \cdot \frac{V_{\text {max }}{ }^{2} \cdot I_{r m s}^{2}}{P^{2}} \\
W C S F_{i} & =\frac{\sum_{j} W_{j}}{W_{i}} \cdot \frac{V_{\text {max }}{ }^{2} \cdot I_{r m s}^{2}}{P^{2}} \\
C C S F_{i} & =\frac{\sum_{j} W_{j}}{W_{i}} \cdot \frac{V_{p k}^{2} \cdot I_{r m s}^{2}}{P^{2}} \\
S C S F & =\sum_{\text {Semiconductors }} S C S F_{i} \\
W C S F & =\sum_{\text {Windings }} W C S F_{i} \\
C C S F & =\sum_{\text {Capacitors }} C C S F_{i}
\end{aligned}
$$

In (15)-(17) $\sum_{j} W_{j}$ represent the total available resources for each component and $W_{i}$ represent the amount of resources assigned to the specific component. In order to minimize the different CSF values, the resources can be differently 
distributed by using the $W_{i}$ weighting factors however, as first iteration the resources are supposed equally distributed. In (18)-(20) each component represents a specific stress; therefore, a CSF comparison requires to compare only components of the same type.

\section{A. CSF Analysis for the Candidate Topologies}

The results from the CSF analysis are presented in Fig. 5. The plots are shown as function of the converters operating voltages and currents on the low voltage side. The converter voltage on the high voltage side is fixed at $750 \mathrm{~V}$ and a summary of the dc-dc converter specifications used for the analysis is presented in Table II. The maximums values have been limited in order to have more comprehensive plots.

From Fig. 5 it can be observed that the values of the IFBBC's CSF (SCSF, WCSF and CCSF shown in Fig. 5a, 5b and $5 \mathrm{c}$ respectively) increase as the converter operating voltage on the LV-side decreases and the values are independent on the operating current. The transformer turns ratio also affects the values of the CSF; in the case of the IFBBC, the transformer turns ratio $n=8$ is chosen in order to minimize the voltage stress on the LV-side power semiconductors. Similarly, the SCSF, WCSF and CCSF values for the DAB topology are presented in Fig. 5d, 5e and $5 \mathrm{f}$ respectively. In this case, all the CSF values vary with both converter voltage and current. This is due to the variation of the phase-shift angle that controls the power flow in the DAB. For all the CSF values of the DAB, there is a minimum defined by the transformer voltage transfer ratio between primary and secondary. In this case, the optimal transformer ratio $n=14$ was selected in the middle of the converter voltage operating range on the LV-side. By varying the number of transformer turns, it is possible to move the CSF minima to other converter operating points.

There is a major difference in the distribution of the CSF values within the two analyzed topologies: for specific operating points, the minimum value of SCSF and CCSF is lower for the $\mathrm{DAB}$ topology compared to the IFBBC. However, the IFBBC has lower WCSF over the entire converter operating range. In all the CSF values the DAB has a minimum at $54 \mathrm{~V}$ and $7 \mathrm{~A}$; while, the IFBBC has always a minimum at $80 \mathrm{~V}$ on the converter LV-side. The major difference in the CSF values is observed for the WCSF: the IFBBC has very low WCSF while these values for the DAB are large due to the large ac-currents and voltages that continuously stress the magnetic components. The CSF values of the IFBBC increase at low voltage levels; this trend is homogeneous over the entire converter operating range. On the other hand, in the DAB, the CSF values widely increase especially at low current levels, when the converter is operating outside its optimal voltage transfer ratio, e.g. $54 \mathrm{~V}$ with $\mathrm{n}=14$.

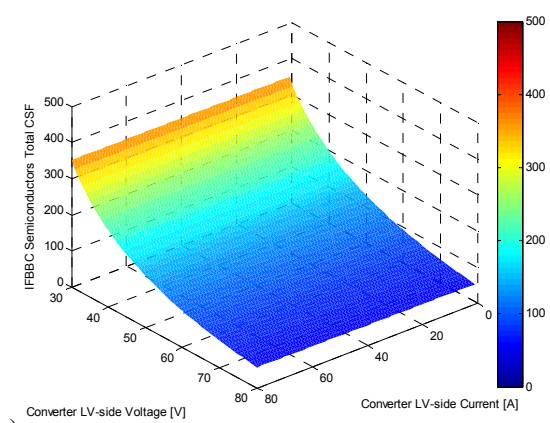

(a) Converter LV-side Voltage $[\mathrm{V}$ (1)

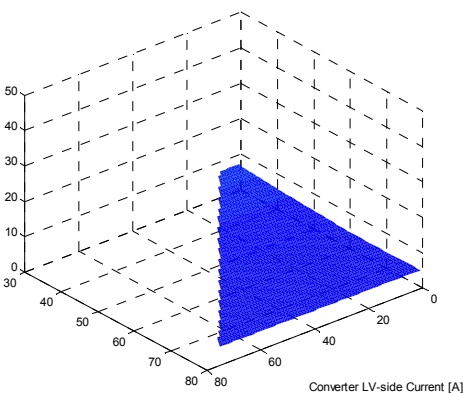

(b) (c) (d)

(e) (f)

Fig. 5 IFBBC topology CSF: SCSF in (a), WCSF in (b) and CCSF in (c). DAB topology CSF: SCSF in (d), WCSF in (e) and CCSF in (f). Black dots in (d) and in (f) represent the intersection between the IFBBC CSF and the DAB CSF values. 
TABLE III

Average CSF VAlues DePending ON THE Operating Mode

\begin{tabular}{lccc}
\hline \hline \multicolumn{1}{c}{ Topology } & SCSF & WCSF & CCSF \\
IFBBC FC-mode & 217.8 & 6.5 & 11.3 \\
DAB FC-mode & 816.3 & 153.1 & 51.0 \\
IFBBC EC-mode & 109.0 & 5.5 & 5.3 \\
DAB EC-mode & 259.7 & 48.7 & 16.2 \\
\hline \hline
\end{tabular}

In order to select the most suitable topology, it is not only necessary to perform a CSF analysis, but it is also necessary to consider the overall system in which the dc-dc converter is expected to operate. Based on the cells stack characteristics presented in Section II, an I-V curve of the cell stack is built for both SOFC and SOEC operating modes [9]. The I-V model is used to determine all converter operating points. The converter CSF values are computed and averaged for all SOFC operating points and for all SOEC operating points. The obtained CSF values for SOFC and SOEC operation of the dcdc converter are presented in Table III.

From the averaged CSF values it is interesting to observe that for both system operating modes (SOFC and SOEC) the average CSF of the IFBBC is significantly lower than the DAB. The IFBBC's average SCSF in FC-mode is $1 / 4$ of the DAB's average SCSF in the same mode. The difference in average SCSF is to $1 / 2-1 / 3$ in EC-mode. Similar differences are observed also in the average CCSF values. The IFBBC's average $\mathrm{CCSF}$ is about five times lower in FC-mode than the $\mathrm{DAB}$; this difference is reduced down to three times for the $\mathrm{EC}$ operating mode. The largest difference is observed in the magnetic components stress factor, in this case the IFBBC has an average WCSF which is almost $1 / 20^{\text {th }}$ in FC-mode and $1 / 10^{\text {th }}$ in EC-mode compared to the DAB's average WCSF. The DAB has a high average WCSF due to the ac current circulating in the transformer windings and to the fixed duty cycle of the phase-shift modulation.

On overall, the IFBBC has lower CSF values and a more homogeneous variation over the entire converter operating range. It should be observed that for fixed operating points the DAB would be preferable. However, when computing

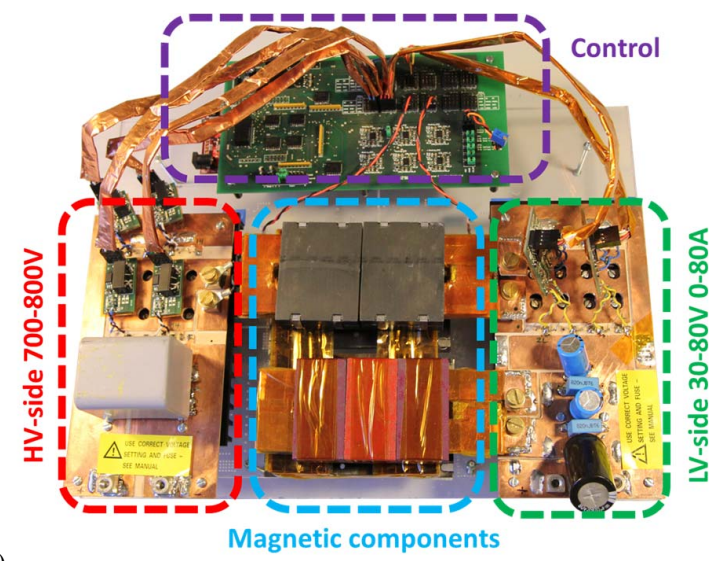

TABLE IV IFBBC DC-DC CONVERTER CHARACTERISTICS

\begin{tabular}{lc}
\hline \hline Voltage primary side (LV) & $30-80 \mathrm{~V}$ \\
Maximum current primary side & $80 \mathrm{~A}$ \\
Voltage secondary side (HV) & $700-800 \mathrm{~V}$ \\
Maximum power & $2400-6400 \mathrm{~W}$ \\
Low Voltage (LV) side MOSFETs & $120 \mathrm{~V} 4.1 \mathrm{~m} \Omega$ TK72E12N1 \\
& 2 in parallel \\
High Voltage (HV) side SiC MOSFETs & SCT30N120 SiC MOS \\
Inductor & C4D15120 SiC diode \\
Inductor core size/material & $20 \mu \mathrm{H}$ \\
Turn ratio n & $3 \times E 6030 \mathrm{KoolMu} 90-26-90$ \\
Transformer core size/material & $1: 8$ \\
Switching frequency & $2 \times E 64$ pairs/Magnetics R \\
\end{tabular}

averaged values, the large CSF values that are observed in nonoptimal operating points of the DAB give large contribution and therefore, they have a large weight on the overall average.

\section{EXPERIMENTAL PROTOTYPE OF A ISOLATED FULL BRIDGE BOOST CONVERTER}

The dc-dc converter for fuel cells is expected to operate with a variety of cells stacks; therefore the dc-dc converter is required to operate over the entire I-V specification in Table I. This requirement is necessary since the SOEC/SOFC technology if not fully mature and variations in the $\mathrm{I}-\mathrm{V}$ characteristics are expected. Moreover, the I-V curve of SOEC/SOEC stacks depends also on the stack operating conditions (temperature, fuel composition, etc.). The IFBBC topology is selected since it has a more homogenous distribution of the CSF thus, a more homogeneous distribution of the converter efficiency is expected.

The converter prototype of a high efficiency IFBBC for bidirectional fuel cells, shown in Fig. 6a, has been developed and tested. The initial converter prototype was based on $\mathrm{Si}$ MOSFETs, Si IGBTs and SiC diodes. This prototype was capable of achieving efficiencies up to $97.8 \%$ and $96.5 \%$ [9][10] depending on the power flow direction. The converter was then updated with $\mathrm{SiC}$ MOSFETs in the full bridge of the converter $\mathrm{HV}$-side. Its main operating waveforms at $60 \mathrm{~V} 80 \mathrm{~A}$ are shown in Fig. $6 \mathrm{~b}$ and a summary of the converter

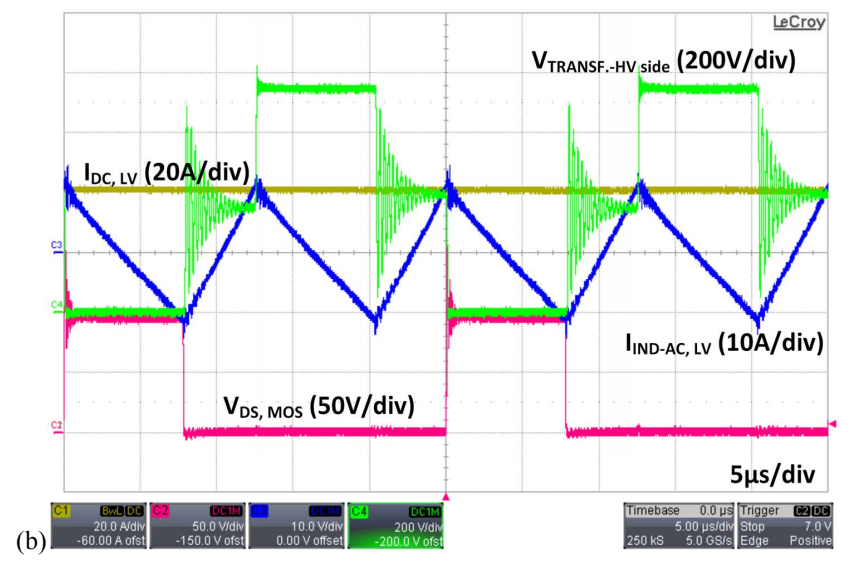

Fig. 6 IFBBC prototype highlighted its main components (a) and main operating waveforms at $60 \mathrm{~V} 80 \mathrm{~A}$ (b). 

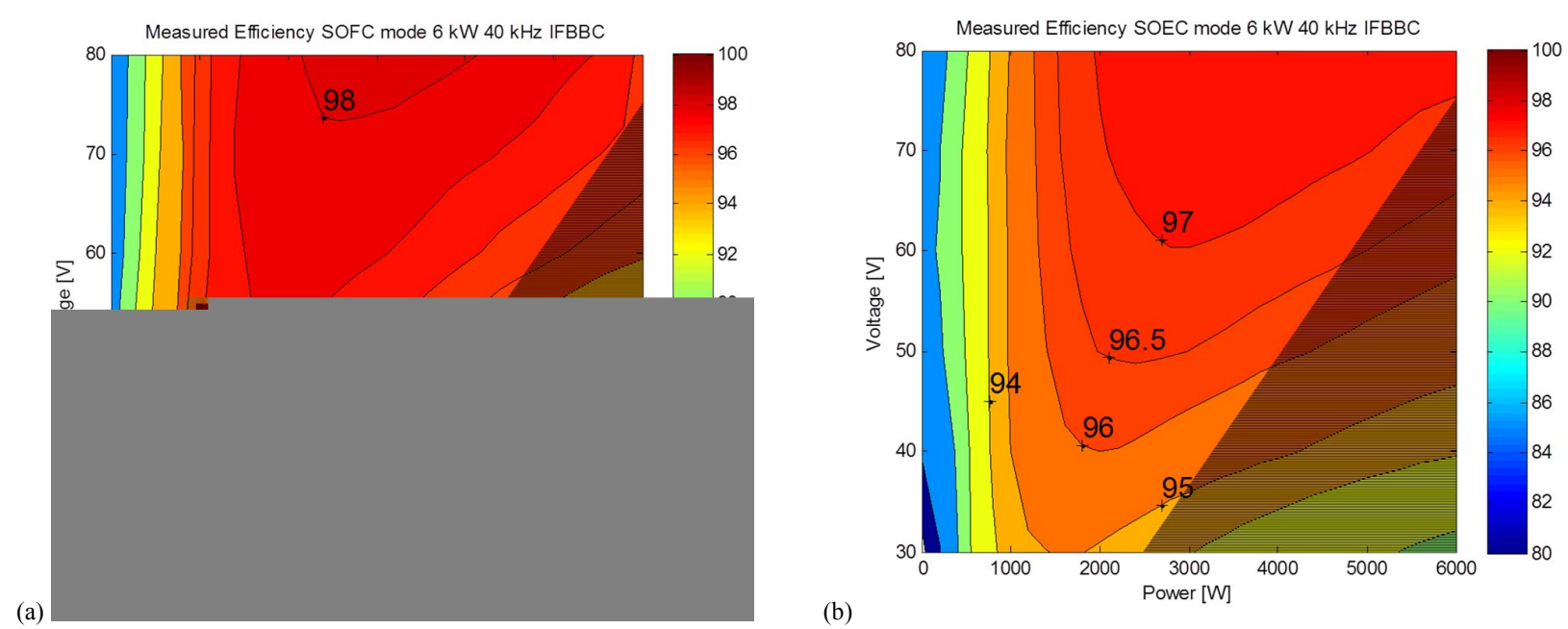

Fig. 7 Measured efficiency of the IFBBC prototype for fuel cell operating mode (a) and for electrolyzer cell operating mode (b). Peak efficiency in SOFC mode $98.2 \%$ and in SOEC mode $97.45 \%$. Darkened area indicates current limitation of the dc-dc converter.

characteristics is presented in Table IV. The converter magnetics are based on custom planar cores in high frequency ferrite for the transformer (Magnetics R-type material) and in distributed gap material (Magnetics KoolMu) for the boost inductor.

The new converter based $\mathrm{SiC}$ active switches is capable of achieving efficiencies up to $98.2 \%$ when operating in fuel cell mode (power flow from the converter LV-side to the HV-side) and up to $97.45 \%$ with reversed power flow, as shown in Fig. $7 \mathrm{a}$ and $7 \mathrm{~b}$ respectively. The highest dc-dc conversion efficiencies are always measured with a current of $\sim 40 \mathrm{~A}$ and at the highest converter voltage on the LV-side $(80 \mathrm{~V})$. At the lowest voltage on the LV-size $(30 \mathrm{~V})$ the converter achieved an efficiency above $96 \%$ and $95 \%$ depending on the direction of the converter power flow, as shown in Fig. $7 \mathrm{a}$ and $7 \mathrm{~b}$.

\section{CONCLUSIONS}

This paper presents a component stress factor (CSF) analysis of the isolated full bridge boost converter (IFBBC) and of the dual active bridge (DAB) operating with phase-shift modulation. The analysis focuses on bidirectional dc-dc converters for fuel cell applications since they require wide operating voltage and current ranges.

The analysis highlights that the DAB has a lower absolute CSF however, the CSF in the DAB rapidly increases as the operating conditions deviate from the optimal operating point. In the $\mathrm{DAB}$, the CSF varies along with both converter voltage and current; while in the IFBBC it depends only on the converter operating voltage. The IFBBC has a lower at average CSF which is also independent from the converter current. The bidirectional fuel cell I-V characteristic has been used to compute an average CSF for both fuel cell and electrolyzer cell operating modes. This highlighted that the IFBBC is a preferable topology for wide operating voltage ranges.

A $6 \mathrm{~kW}(30-80 \mathrm{~V} 80$ A boosted up to $700-800 \mathrm{~V})$ converter prototype of an IFBBC has been developed. The converter is based on high current fully planar magnetics and is capable of achieving peak efficiency of $98.2 \%$ in fuel cell mode and of $97.45 \%$ in regenerative mode.

\section{REFERENCES}

[1] Hirose, T.; Nishimura, K.; Kimura, T.; Matsuo, H., "An ac-link bidirectional DC-DC converter with synchronous rectifier," IECON 2010 - 36th Annual Conference on IEEE Industrial Electronics Society, pp.351,357, 7-10 Nov. 2010.

[2] Nymand, M.; Andersen, M. A E, "High-Efficiency Isolated Boost DCDC Converter for High-Power Low-Voltage Fuel-Cell Applications," IEEE Transactions on Industrial Electronics, vol.57, no.2, pp.505,514, Feb. 2010.

[3] Biela, J.; Schweizer, M.; Waffler, S.; Kolar, J.W., "SiC versus SiEvaluation of Potentials for Performance Improvement of Inverter and DC-DC Converter Systems by SiC Power Semiconductors," IEEE Transactions on Industrial Electronics, vol.58, no.7, pp.2872,2882, July 2011.

[4] Barton, J.P.; Infield, D.G., "Energy storage and its use with intermittent renewable energy," Energy Conversion, IEEE Transactions on , vol.19, no.2, pp.441,448, June 2004.

[5] J. D. Maclay, J.Brouwer, G. S.Samuelsen, "Dynamic modeling of hybrid energy storage systems coupled to photovoltaic generation in residential applications", 2007 Journal of Power Sources, vol.163, issue 2, pp. 916925.

[6] Kheraluwala, M.N.; Gascoigne, R.W.; Divan, D.M.; Baumann, E.D., "Performance characterization of a high-power dual active bridge DCto-DC converter," IEEE Transactions on Industry Applications, vol.28, no.6, pp.1294,1301, Nov/Dec 1992.

[7] Bruce Carsten, "Converter Component Load Factors; A Performance Limitation of Various Topologies," in PCI, Munich, 1988.

[8] Petersen, L.; and Michael Andersen, "Two-Stage Power Factor Corrected Power Supplies: the Low Component-Stress Approach," in Applied Power Electronics Conference and Exposition (APEC), 2002.

[9] Pittini, R.; Zhe Zhang; Andersen, M.A.E., "Analysis of DC/DC converter efficiency for energy storage system based on bidirectional fuel cells," Innovative Smart Grid Technologies Europe (ISGT EUROPE), 2013 4th IEEE/PES, pp.1,5, 6-9 Oct. 2013.

[10] Pittini, R.; Zhe Zhang; Andersen, M.A.E., " Isolated Full Bridge Boost DC-DC Converter Designed for Bidirectional Operation of Fuel Cells/Electrolyzer Cells in Grid-Tie Applications" $15^{\text {th }}$ European Conference on Power Electronics and Applications (EPE-ECCE Europe 2013), 3-5 September 2013. 